\title{
Implementação de um Repositório Organizacional on- line de processos em uma instituição pública de ensino
}

\author{
Alessandra Carla Ceolin - alessandra.acc@gmail.com ${ }^{1}$ \\ Ana Clara Cavalcante de Miranda - clara.acmiranda@gmail.com ${ }^{1}$ \\ Marco Aurélio Benevides de Pinho - marcoabpinho@gmail.com ${ }^{1}$ \\ Marcelo Brito Carneiro Leão - marcelo.leao@ufrpe.br ${ }^{1}$
}

\begin{abstract}
Resumo - Ao considerar-se o valor do conhecimento e do mapeamento de processos, surge a necessidade da existência de um ambiente colaborativo e integrado que concentre as modelagens de processos para consulta e utilização de seus usuários. Esta pesquisa busca analisar os principais fatores críticos de sucesso na implementação de um repositório de processos on-line em uma instituição pública. Utilizou-se como coleta de dados a realização de entrevistas com dois stakeholders diretamente envolvidos no projeto, bem como, a análise do sistema implantado. Os principais resultados apontam que o planejamento é um dos principais pontos a considerar para realizar um bom gerenciamento de processos. A implementação do repositório on-line contou com esse planejamento ao dialogar com o Plano de Desenvolvimento Institucional, comprometendo-se assim a colaborar no crescimento e disseminação de conhecimento na universidade.
\end{abstract}

Palavras-chave: Inovação Organizacional; Gestão de Processos; Administração Pública.

\section{Implementation of an online organizational repository of processes in a public education institution}

\begin{abstract}
When considering the value of knowledge and process mapping, there is a need for a collaborative and integrated environment that concentrates process modeling for consultation and usage by its users. This research aims analyzes the main critical success factors in the implementation of an online process repository in a public institution. Interviews with two stakeholders directly involved in the project were used as data collection, as well as the analysis of the implemented system. The main results indicate that planning is one of the main points to consider in order to perform a good process management. The implementation of the online repository relied on this planning since it was aligned with the Institutional Development Plan, thus committing to collaborate in the growth and dissemination of knowledge at the university.
\end{abstract}

Keywords: Organizational Innovation; Processes management; Public administration 


\section{INTRODUÇÃO}

Diante de um mundo globalizado e com informações sendo geradas de forma cada vez mais rápidas, faz-se necessário pensar em novas formas de compartilhar o modo de execução das diferentes operações nas organizações. Neste universo de informações é essencial que os procedimentos sejam cada vez mais claros e coesos, visando a facilidade de compressão e execução. Em diversas instituições públicas esse compartilhamento de informações ainda é visto com temor, por receio de perder seu posto de trabalho e em outros casos, a falta de uma gerência coesa faz com que um procedimento impreciso se perpetue por anos, não se aprimorando através de novas tecnologias.

Além disso, os processos ganham cada vez mais novos procedimentos, tudo isso sem um gerenciamento adequado ou um registro que possa ser compartilhado, existindo somente o conhecimento de quem executa diariamente. Por muitas vezes as demandas de serviços nos setores podem até ser iguais em uma mesma instituição, contudo, são executadas utilizando métodos totalmente diferentes. Diante desta realidade se faz importante um ambiente colaborativo, no qual sejam armazenados mapeamentos dos processos destas instituições.

Uma das formas de saber qual a melhor maneira de gerenciar os processos, é saber quais os seus fatores críticos de sucesso, percebendo qual as melhores ações traçadas e que de fato apresentam resultados. Priorizar assim os pontos atendidos para que a gestão de processo tenha o melhor resultado, ou ainda são as áreas que normalmente se deve ter a maior atenção para que os objetivos sejam devidamente alcançados.

A revisão de literatura desta pesquisa discorre sobre gestão de processos, e de como se encontra a implementação na execução de repositório de processos on-line. Como procedimento metodológico foi utilizada uma abordagem exploratória descritiva, a partir da análise dos softwares e da realização de entrevistas com stakeholders que estão envolvidos na construção deste sistema, apresentando como objetivo identificar os principais fatores críticos de sucesso ao longo do mapeamento para o desenvolvimento do Repositório Organizacional On-line de Processos da Universidade Federal Rural de Pernambuco (REPORG/ UFRPE).

\section{FATORES CRÍTICOS DE SUCESSO E UMA ESTRUTURA PARA COMPARTILHA- MENTO DE MAPEAMENTO DE PROCESSOS}

A abordagem administrativa da gestão por processos é também conhecida como abordagem sistêmica para gestão das organizações, por ter utilizado para sua formulação e fundamentação a Teoria Geral dos Sistemas (SORDI, 20I4). Assim, esta teoria direciona a análise do pesquisador para o todo, ou seja, para as relações entre as partes que se interconectam e interagem orgânica e estatisticamente.

Segundo Gonçalves (2000) processo pode ser tomado como sendo qualquer atividade ou conjunto de atividades que toma um input, adiciona valor a ele e fornece um output a um cliente específico. Assim, a organização do trabalho em uma visão por processo toma como base o pensamento sistêmico, que envolve uma mudança das partes para o todo, da percepção dos ob- 
jetos para as relações de interdependência entre fornecedores, executores e clientes, das estruturas para os processos, da integração e do crescimento para a sustentabilidade (ASSUNÇÃO; MENDES, 2000).

As autoras Assunção e Mendes (2000) ainda afirmam que a gestão de processo gera o resultado esperado quando o ambiente corporativo é favorável e a sua estrutura global interligue outros instrumentos administrativos, como por exemplo: planejamento estratégico, sistema de participação, qualidade total, relatórios gerenciais, estrutura organizacional, logística e comprometimento de funcionários. Além disto, é possível observar que uma boa gestão de processos apresenta procedimentos metodológicos adequados, facilidade de acesso, cumprimento fidedigno de normas, bem como regras internas claras e precisas.

Dentro desse contexto, o tratamento da informação é um meio para gerenciar melhor dados dentro das instituições, já que o acesso às informações ajuda a encontrar as melhores soluções e tomar decisões adequadas. Deste modo, gerenciar as entradas e saídas das informações é imprescindível, assim como acompanhar o tempo e o caminho percorrido até chegada aos setores correspondentes.

Informações processadas ajudam as ações empresariais, conforme Mcgee e Prusak (I994, p. 24), informação são "dados coletados, organizados, ordenados, aos quais são atribuídos significados e contexto". Com a tecnologia informacional em alta, a gestão da informação encontrou um suporte contundente, segundo O'Brien (2002) o sistema gerencial auxilia aos gestores a tomarem as melhores decisões. Isto faz com que os seus processos sejam reavaliados continuamente, a fim de buscar as melhores soluções.

Na década de 80 do século XX, começou-se a falar de Gestão da Informação (GI). Trauth (I989, p. 258) apresenta três bases da GI: "a gestão de dados, de documentos e de processos de informação". Sendo que o objetivo da GI é auxiliar organizações e seus stakeholders a acessar e processar informações de forma eficiente e eficaz (DETLOR, 20IO).

Dentro da GI encontra-se a Gestão de Processos (GP), que promove todo o planejamento, avaliação e direção de forma a obter uma sequência de atividades voltadas a atender os clientes de forma eficaz, com o mínimo de conflitos e o máximo de produtividade. Pois, "a qualidade dos processos está diretamente relacionada com o sucesso organizacional" (BERTUCCI, 2005, p. I4).

Dessa forma, faz-se necessário uma organização do processo da informação através do mapeamento. Para Espantoso (20I2), a arquitetura da informação apresenta similitudes com a arquitetura convencional, ambas apresentam como objeto de estudo o projeto de estruturas práticas, considerando aspectos funcionais e estéticos que viabilizem o fluxo em seus ambientes, tornando exequíveis os recursos disponíveis.

A arquitetura hierárquica de processos significa a introdução de uma linguagem e conceitos fundamentais de processo com foco nas necessidades do cliente (SMART et al., 2008). 
Para melhor fundamentar esse conceito, pode-se relacionar os Fatores Críticos de Sucesso (FCS) que apresentam os melhores percursos dentro do caminho dos processos, retirando falhas e ambiguidades.

Lopes e Bezerra (2008) indicaram oito fatores críticos de sucesso para a implantação da gestão por processos: (I) seleção e capacitações dos líderes do projeto; (2) sensibilização e envolvimento dos participantes do projeto; (3) divisão do trabalho de acordo com os conhecimentos, habilidades e atitudes; (4) conhecimento técnico dos processos; (5) envolvimento e motivação dos operadores dos processos; (6) disponibilidade de técnicos e gerentes para atuar nas diferentes fases do projeto; (7) sistema de acompanhamento de resultados funcional; e, (8) divisão do trabalho de acordo com as finalidades de processos.

Os fatores citados anteriormente se interligam de uma forma que precisam ser todos integrados ao mesmo tempo, faz-se necessário selecionar bem os recursos humanos disponíveis para que possam trabalhar de forma conceitual e prática (RODRIGUEZ, 2002). Após isto, com bons líderes fica mais fácil sensibilizar todos os envolvidos no projeto e com todos sensibilizados a próxima etapa é dividir bem os trabalhos, cada qual com suas habilidades, não perdendo o foco de sua motivação para que os processos sejam bem realizados. Então, com o corpo de recursos humanos disponível para que tudo aconteça de forma mais ordenada, a tendência é que o processo faça o caminho adequado. Depois disso, anotar e perceber o conhecimento que as pessoas produzem ao tramitar com os processos; sempre buscando acompanhar a localização do processo, fazendo o seu desenho.

O trabalho com os FCS partiu de Rockart (1979), constituindo-se em uma inovação metodológica na gestão por processos e fortaleceu a competitividade da empresa. Os FCS podem auxiliar na formação de competências para as pessoas que irão trabalhar diretamente com a gestão de processos. O serviço público também possui uma grande demanda por gestão de processos. Sendo que muitas vezes o sistema ou aporte tecnológico não é utilizado, existindo somente no manual e na rotina das pessoas que executam as atividades.

Assim, pode ser perigoso considerar que simplesmente copiando os processos de negócios bem-sucedidos de uma empresa privada, por exemplo, seja possível obter os mesmos benefícios, pois cada organização deve estudar cuidadosamente suas contingências e alinhar adequadamente seus programas de gerenciamento de processos (TRKMAN, 20IO).

Vale lembrar, neste ponto, que Jurisch et al. (2013) realizaram levantamento de I28 estudos de casos, envolvendo projetos de reengenharia de processos em organizações públicas e privadas; observou-se que os projetos foram considerados exitosos em $60 \%$ das entidades públicas e em $70 \%$ das privadas; além disso, em um maior número de instituições públicas os projetos ficaram incompletos (23\%), na comparação com as demais (I4\%).

Maia e Pinho (20I8) chamam a atenção para o campo pouco reconhecido, porém de grande importância, da influência das pessoas e culturas organizacionais no mapeamento de processos. Harrison-Broninski (20I4) salienta a necessidade de distinção entre os processos 
centrados nas pessoas (como o processamento de pedidos comerciais, a aprovação de empréstimos ou o atendimento ao cliente, em que indivíduos interagem com políticas organizacionais, protocolos, banco de dados e, apenas de forma limitada, com outras pessoas) e os chamados Human-Driven Processes (HDP's) em que a busca por colaboração, adaptação e inovação tornam a liderança humana indispensável.

Não é difícil perceber que algumas das principais etapas do mapeamento de processos constituem, elas mesmas, HDP's - particularmente em organizações complexas como universidades, institutos de pesquisa, ou agências proponentes/ executoras de políticas públicas; são ambientes em que, não raras vezes, atividades específicas são executadas por profissionais com elevado grau de especialização, a partir de conhecimentos, habilidades e modelos mentais dificilmente compartilhados por outros atores envolvidos na execução do mesmo processo (GUISE et al., 20I7).

Compreende-se, então, ser necessário desenvolver uma visão holística da organização, seja ela pública ou privada, para que uma vez implantados os processos, tenham continuidade e alcancem seus objetivos. É necessário atuar junto aos colaboradores, nos equipamentos e sistemas e no próprio repositório (BALDAM et al., 2007). Assim, a parte estrutural precisa ser bem trabalhada, devendo ser considerada a cultura da organização, considerando uma visão sistêmica dos processos (figura I).

FIGURA I - Visão sistêmica dos processos

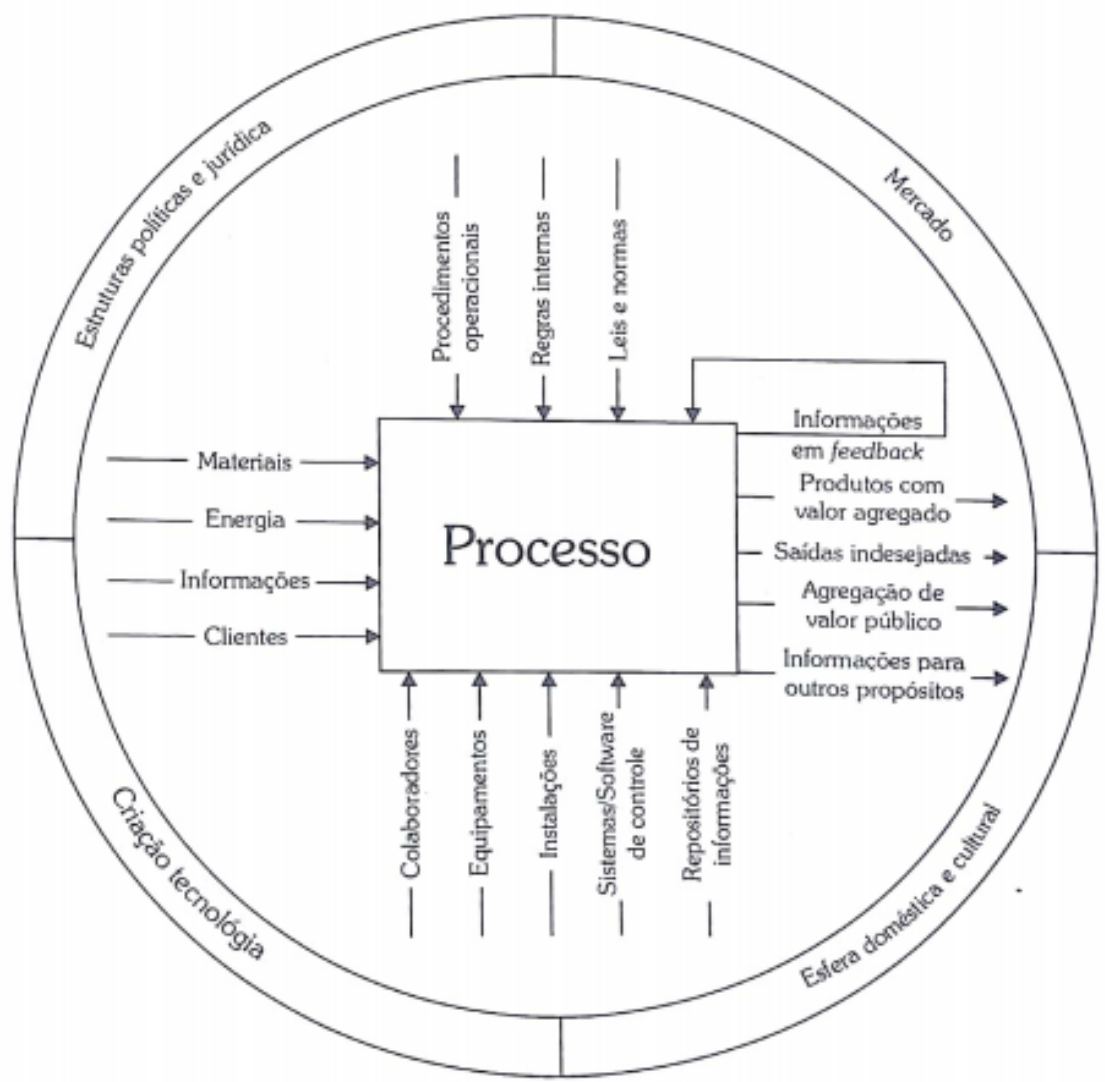

Fonte: Baldam et al. (2007, p.2I) 
Conforme o apresentado na figura I, o fornecimento ideal para uma boa gestão de processos com procedimentos metodológicos adequados são as regras internas claras e precisas, além de uma boa divulgação, com o cumprimento fidedigno de leis e normas fazendo toda a diferença para que seja apresentado ao mercado um serviço de processos eficiente e que não pare nos mesmos procedimentos, mas esteja em constante mudança, promovendo sempre avanços operacionais.

Portanto, em vez de serem relegados à uma genérica "cultura organizacional", ou atribuídos a posturas pessoais e profissionais (in) adequadas de indivíduos, os fatores comportamentais envolvidos na execução de processos organizacionais críticos - bem como seus impactos - devem ser investigados como aspecto passíveis de planejamentos e gestão (MAIA; PINHO, 20I8).

\section{METODOLOGIA}

Visando a definição da amostra a ser pesquisada, pode-se delimitar o campo de pesquisa em termos temporais, geográficos, setoriais ou qualquer outra dimensão cabível, com base na disponibilidade ou obtenibilidade de dados ou com o fundamento nos objetivos e nos custos da execução da pesquisa (LEITE, I978, p. 79).

Dessa forma, na presente pesquisa, foram selecionadas (a partir do interesse dos pesquisadores, da disponibilidade, da acessibilidade e da completude de informações) duas pessoas capacitadas/interessadas (stakeholders) que estão diretamente ligadas aos processos de implementação do Repositório on-line. O stakeholder I é professor da universidade, foi pró-reitor de planejamento da instituição, é estudioso da área de processos, participa do Fórum Nacional de Pró-Reitores de Planejamento e de Administração das Instituições Federais de Ensino Superior (FORPLAD) e é o propositor do repositório on-line de processos. O stakeholder 2 também é professor da instituição, participa ativamente da gestão da universidade (atuando na reitoria) e é coordenador do Comitê Gestor de Tecnologia da Informação.

A presente pesquisa possui aspectos exploratórios e descritivos, envolvendo entrevistas com duas pessoas que possuem experiência prática com o problema pesquisado. Segundo Chizzotti (I99I, p. 57) esta técnica é um tipo de comunicação entre um pesquisador que pretende colher informações sobre fenômenos e indivíduos que detenham essas informações e possam emiti-las. Além da realização de entrevistas, é apresentada uma ferramenta de com função de repositório - o Ágora Project - que já está implantado e em funcionamento.

Tanto as entrevistas quanto a apresentação do website, buscam levantar propostas para mudanças e contribuir para o desenvolvimento do repositório on-line de processos da UFRPE. Para realizar a análise dos resultados foi utilizada a análise do discurso, a partir da coleta realizada nas entrevistas, as quais foram gravadas e transcritas. Foi utilizada a marca do discurso como sendo a importância da implementação do REPORG e seus fatores críticos de sucesso. A análise do discurso torna-se ainda conveniente para esta pesquisa por ser uma análise vertical da entrevista como apresentam Caregnato e Mutti (2006). Qualquer elemento pode ser estudado enquanto marca linguística, ou de discurso, podendo ser selecionadas poucas marcas linguísticas para interpretação. 


\section{RESULTADOS}

A administração pública em nosso país procura alinhar cada vez mais as práticas de modernidade de gestão, com serviços eficientes ao utilizar recursos públicos que possam dar uma resposta satisfatória a todos os clientes, para que ocorra de fato um trabalho efetivo e transparente. Assim como traz a emenda constitucional de número I9, de 1998 da Constituição de 1988 que diz em seu artigo 37: "a administração pública direta e indireta de qualquer dos Poderes da União, dos Estados, do Distrito Federal e dos Municípios obedecerá aos princípios de legalidade, impessoalidade, moralidade, publicidade e eficiência” (BRASIL, I988).

Também é importante considerar o artigo $2^{\circ}$, inciso II da Lei 13460/17, que dispõe sobre participação, proteção e defesa dos direitos do usuário dos serviços públicos da administração pública, delimita que "serviço público é a atividade administrativa ou de prestação direta ou indireta de bens ou serviços à população, exercida por órgão ou entidade da administração pública" (BRASIL, 20I7). Ainda, segundo a esta Lei, em seu artigo $4^{\circ}$, "os serviços públicos e o atendimento do usuário serão realizados de forma adequada, observados os princípios da regularidade, continuidade, efetividade, segurança, atualidade, generalidade, transparência e cortesia" (BRASIL, 20I7).

Não se pode deixar de frisar que a gestão das universidades federais brasileiras vem passando por profundas transformações, trazidas pela edição de normativas internas e externas, pela emergência de novas tecnologias e pela necessidade de atender novas demandas sociais. $\mathrm{Na}$ tentativa de revisar e aperfeiçoar seus processos organizacionais, a Instituição Federal do Ensino Superior (IFES) encontra severos obstáculos na disponibilidade e no melhor uso de recursos: faltam servidores técnicos qualificados e ferramentas (software e hardware), enquanto sobram iniciativas fragmentárias e descontínuas.

Essa problemática foi levantada em uma das reuniões do Fórum Nacional de Pró-Reitores de Planejamento e de Administração das Instituições Federais de Ensino Superior (FORPLAD) que se trata de reuniões de pró-reitores tanto de planejamento quanto de administração. Esses encontros ocorrem normalmente quatro vezes por ano e tem como objetivo propor soluções relacionadas as áreas de planejamento enfrentadas pelas IFES, como também busca fazer o intercâmbio em temas de interesse mútuo, consolidar documentações e assessorar os dirigentes. Com esses objetivos, um dos planos de ação de 2018 e 2019 foi a criação em um grupo de Gestão de Processos, para que se pudesse obter um espaço de gestão nacional de troca colaborativa de mapeamento de processos das instituições de educação a nível federal.

Para entender este ponto, observa-se no quadro I, que o stakeholder I explica como foi desenvolvido um grupo de gestão de processos institucional. 
QUADRO I - Entrevista com stakeholder I sobre os passos iniciais

Quais foram os primeiros passos para a construção do Repositório on-line e o porquê da escolha da UFRPE para ser pioneira nessa trajetória?

O FOPLAD, Fórum de pró-reitores de administração e planejamento é uma organização que trabalha para a Associação Nacional de reitores. Logo abaixo da associação de reitores tem a associação de pró-reitores. Por sua vez, o FORPLAD tem uma rotatividade muito grande, a cada reunião tem professores que estão terminando seus mandatos, tem outros que estão começando, com uma variação constante. Com isto, quando se organizam para fazer um projeto mais duradouro definem grupos de trabalhos.

Há dois anos foi criado o grupo de Gestão de Processos, só que por causa da rotatividade de pró-reitores na FORPLAD a formação do grupo de pessoas que idealizou se desfez e quem assumiu não deu continuidade e quase que seria extinto. Para que isto não ocorresse a UFRPE ofereceu seus serviços para dar continuidade com este grupo e conduzir essa pauta.

A universidade está procurando assim uma articulação nacional para a condução de mapeamento de processos pelas IFES que contribuiriam internamente mediante as prioridades que cada uma, mas também visa que existam editais nacionais nas quais todas as IFES participantes possam convergir para determinadas áreas da gestão pública. O projeto está na fase de propostas e adequações para poder então ser executado, estando a UFRPE à frente dessa pauta de forma voluntária.

Fonte: Elaborado pelos autores

De acordo com a resposta encontrada no quadro I, o stakeholder I afirma: "A universidade está procurando assim uma articulação nacional". A universidade apresentada trata-se da UFRPE, que segundo o entrevistado, propôs seus serviços para dar movimento no grupo criado para facilitar o compartilhamento de processos. A UFRPE então lidera essa iniciativa a nível nacional, e com isso, a dar continuidade ao desenvolvimento do nível de planejamento da educação pública superior, no que tange a gestão de processos. Organizou-se então um grupo dentro da UFRPE para se discutir sobre a gestão de processos e a sua organização atual dentro da instituição, pois pelo que se conhece, ocorre a inexistência ou insuficiência de documentações de como seriam realizadas as atividades, ou então, os processos das atividades se encontram na cabeça de poucas pessoas, o que torna a execução processual ineficiente e sem controle.

No quadro 2, o stakeholder I apresenta em sua resposta o ambiente utilizado para a criação do repositório on-line da UFRPE. Este ambiente trata-se de um software livre chamado Ágora Project que é de origem francesa, e possui um código aberto, sendo a licença ofertada por ele de uma possibilidade grande de variações para a sua utilização, compreendendo em seu uso muitas possibilidades de adequação às necessidades da universidade. Ainda de acordo com a resposta contida no quadro 2 este software está abrigado em um servidor público da UFRPE, integralmente dentro da lei e das regulações. 
QUADRO 2 - Entrevista com stakeholder I sobre o sistema escolhido

\begin{tabular}{|l|}
\hline Por que este sistema foi escolhido? \\
O software que a UFRPE utiliza é o Ágora Project, utilizado para o desenvolvimento de trabalho em \\
grupo que possui licença ampla, o que significa que é um open source, ou seja, é um código aberto, com isso \\
além de poder usá-lo e implantá-lo pode também ser utilizado para fins comerciais particulares, o que não se \\
pode é fazer exploração comercial do software. Como então já existe um software livre e gratuito que permite \\
a utilização e a colaboração on-line não se faz necessário criar um novo dentro da instituição. \\
É bom deixar ciente que o Ágora não é exclusivo para a gestão de processos como existem alguns no \\
mercado, mas estes são privados e para serem utilizados na rede pública deveriam ser adquiridos por toda \\
forma de licitações por todas as instituições que gostariam de contribuir com a plataforma colaborativa. Então \\
a gratuidade e completude é a razão principal que está se utilizando o Ágora Project, que apesar de não ser \\
específico para processos, permite a articulação de equipes e tarefas, com a finalidade de ser um software \\
de trabalho em grupo. Apesar do software possuir o acesso a três línguas que não o português, hoje em dia \\
com a tecnologia on-line é possível dispor de um plug-in que adiciona um elemento no navegador, o que torna \\
possível a tradução automática para o português.
\end{tabular}

Fonte: Elaborado pelos autores

Como apresentado no quadro 2 o repositório on-line de processos da UFRPE é desenvolvido no sistema do Ágora Project, chama-se Repositório Colaborativo de Processos Organizacionais (REPORG) e já está instalado no servidor da universidade, no endereço: http:// app.decon.ufrpe.br/agoraproject/?ctrl=dashboard. (Quadro 2). O acesso ocorre através de senhas concedidas pelos gerenciadores do repositório.

O REPORG é um ambiente colaborativo onde se desenvolve, amplia e dissemina as práticas de gestão de processos nas universidades, sendo um espaço de interação e de construção do repositório em que as pessoas podem de maneira colaborativa contribui para a constituição desse acervo. Segundo Baldam et al. (2007) a formação de repositório facilita a implantação de processos e outros negócios que são testados de forma prévia, para que se integrem seus conteúdos similares.

Na figura 2 é apresentada a página inicial do REPORG. Ela assemelha-se a uma entrada comum de outros ambientes, utilizando-se login e senha. As permissões do acesso são definidas por perfis e gerenciadas somente pelo administrador do REPORG.

FIGURA 2 - Página de entrada do REPORG

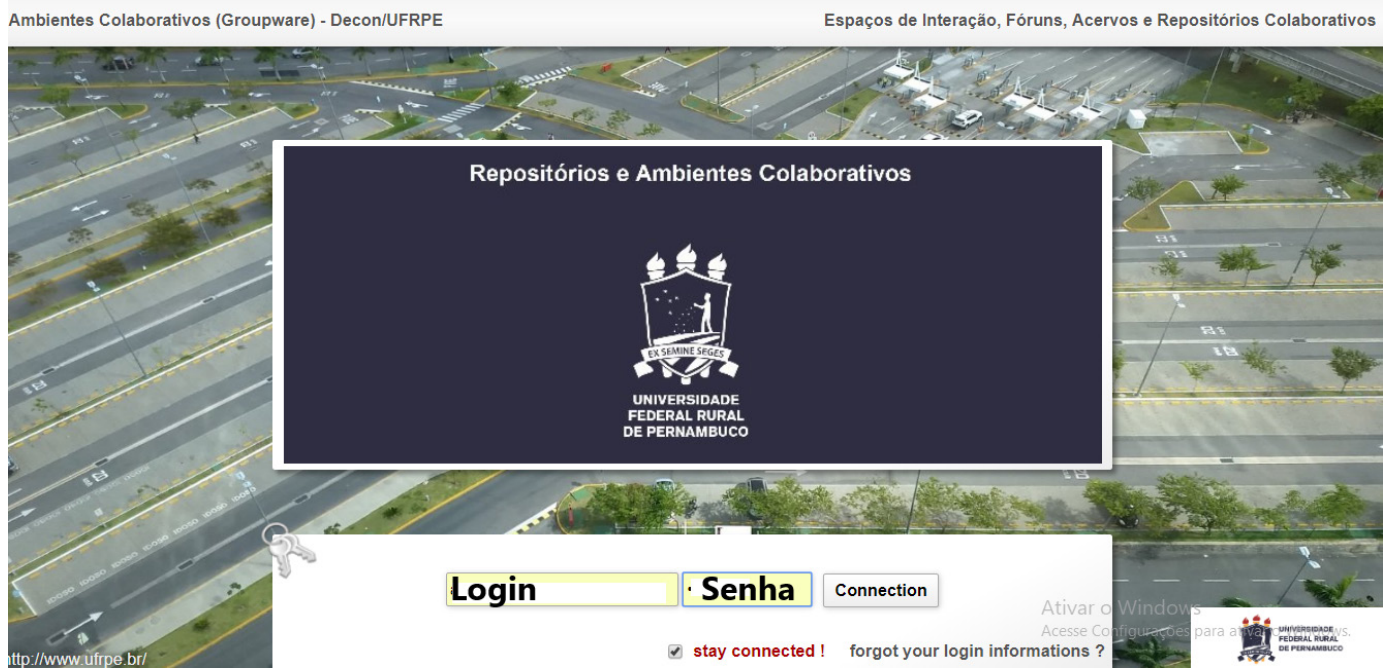

Fonte: site do REPORG (UFRPE, 20I8) 
Como qualquer site que se possui perfis individuais pede-se para fazer o login, no caso do repositório como realiza-se com o e-mail e senha (Figura 2). O REPORG foi pensado para acessos individuais que se possa registrar as ações e contribuições de cada colaborador dentro do ambiente. É uma forma do usuário sentir confiança no sistema, pois, a "identificação individual, controle de senhas, acesso à informação confidencial e cópias de segurança são as primeiras preocupações da organização" (FONTES, 2008, p. 206).

Ao fazer o login e inserir a senha, o colaborador é encaminhado para a página principal do REPORG, que se apresenta então todas as ferramentas que o software possui. A figura 3 traz algumas dessas funções dentro do REPORG, o que envolve várias funcionalidades (UFRPE, 20I8)

FIGURA 3 - Página principal do REPORG

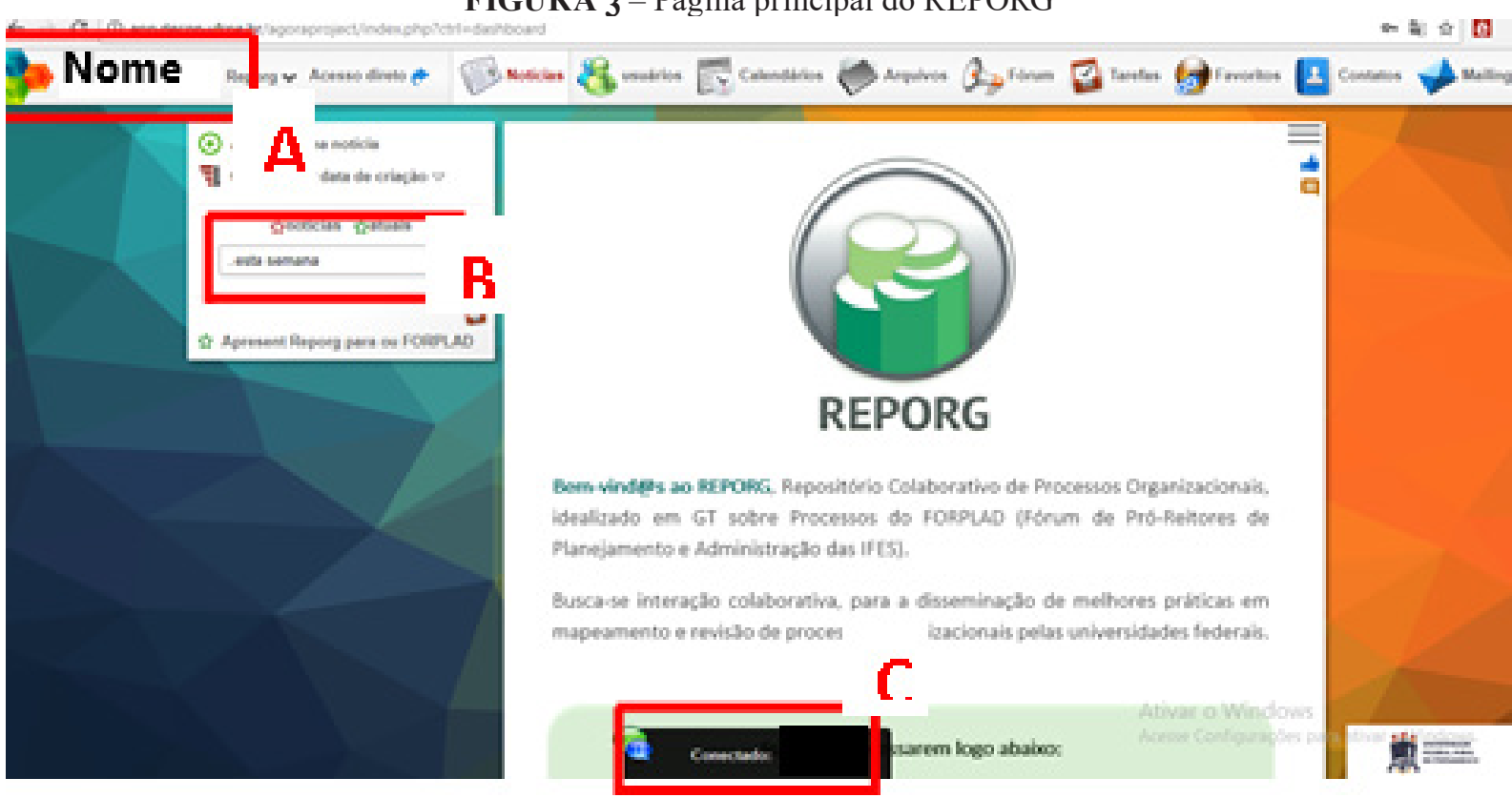

Fonte: site do REPORG (UFRPE, 20I8)

A letra " $A$ " da figura 3, apresenta o acesso ao perfil do colaborador, onde é possível mudar de senha, sair do repositório e mandar mensagens instantâneas. A letra "B" apresenta uma funcionalidade semelhante com um feed de notícias, o qual estarão disponíveis as publicações mais recentes por parte de todos os colaboradores, e para encerrar o trato da figura 3 a letra " C" configura-se na apresentação dos colaboradores que estão on-line ao mesmo tempo que for realizado o acesso.

O repositório on-line de processos da UFRPE apresenta-se então como um site de fácil acesso, semelhante a outros sites de colaboração. Para facilitar a interação e entendimento das funcionalidades do repositório existe um vídeo disponibilizado na página principal do REPORG que conta a história de sua construção e as ferramentas que nele se apresenta.

Uma vez que se trata de um ambiente colaborativo, é importante que os colaboradores conheçam uns aos outros, saibam por quem as universidades estão representadas e consigam os 
contatos necessários. Observa-se que o repositório da UFRPE possui um ícone que é possível procurar por cada colaborador presente.

Neste repositório implantado no Ágora Project pode-se criar grupos com seus usuários. É possível fazer a ordenação dos usuários por ordem alfabética e fazer essa apresentação visual em blocos ou em lista. Essa interação entre os usuários num ambiente colaborativo torna-se essencial para o seu bom desempenho, como afirma Brito e Pereira (2004) que se torna compreensível para que as informações circulem entre os usuários dentro do ambiente.

Outra forma que se pode mostrar a interação entre os colaboradores dentro do repositório está configurada na figura 4, trata-se de uma agenda que pode ser de uso individual, ou pode marcar outros colaboradores para que não se esqueçam de datas importantes para o desenvolvimento de colaboração nos processos.

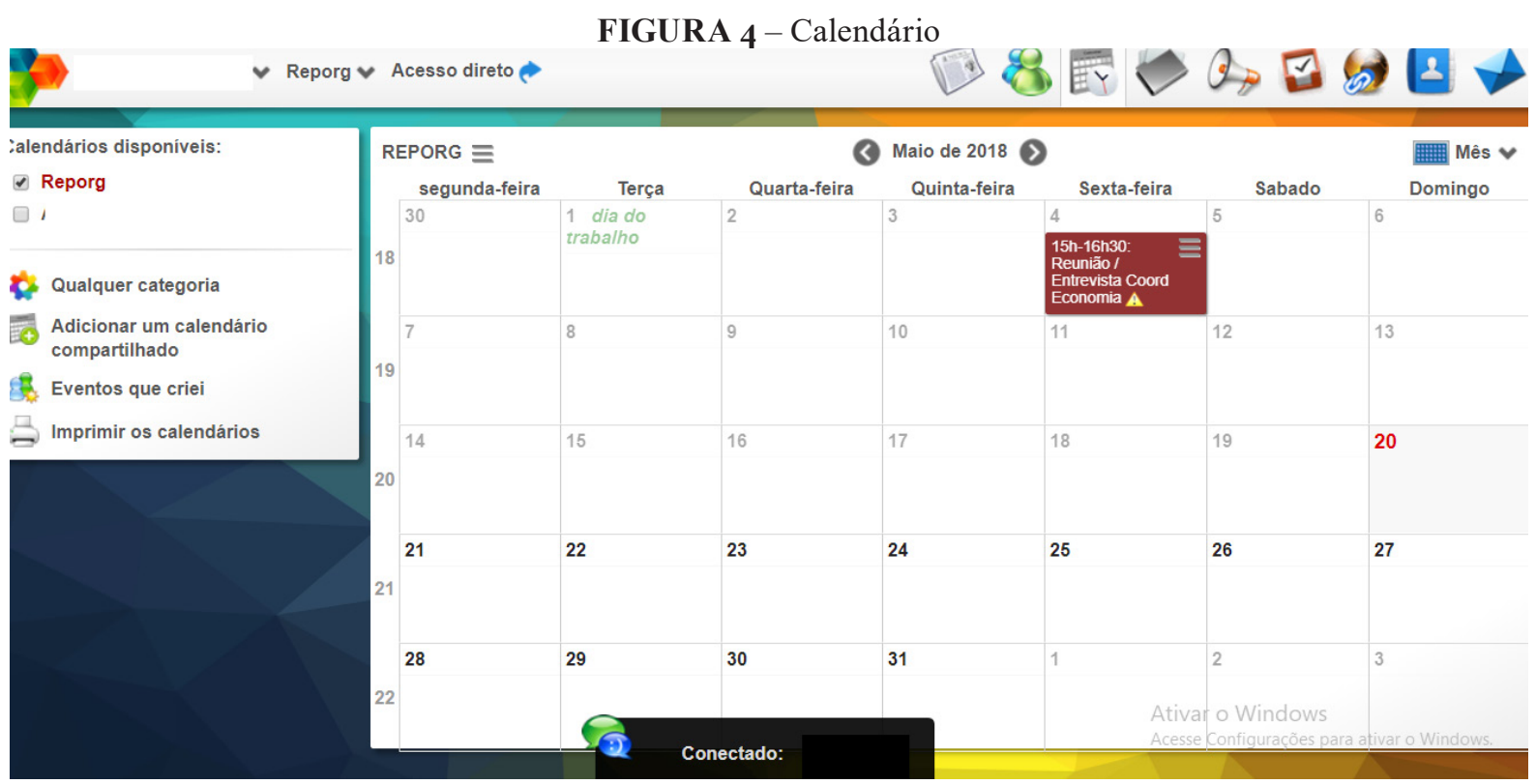

Fonte: site do REPORG (UFRPE, 20I8)

O calendário num ambiente colaborativo permite que outras pessoas saibam o que se pretende fazer dentro daquele espaço num determinado prazo de tempo, ou até compartilhar agendas quando se for marcar reuniões, entre os usuários, como observa-se na tela de agenda do repositório.

Uma das funções mais importantes dentro do repositório ocorre dentro da administração de arquivos, sendo nesse espaço um local propício para organização de arquivos (figura 5). 


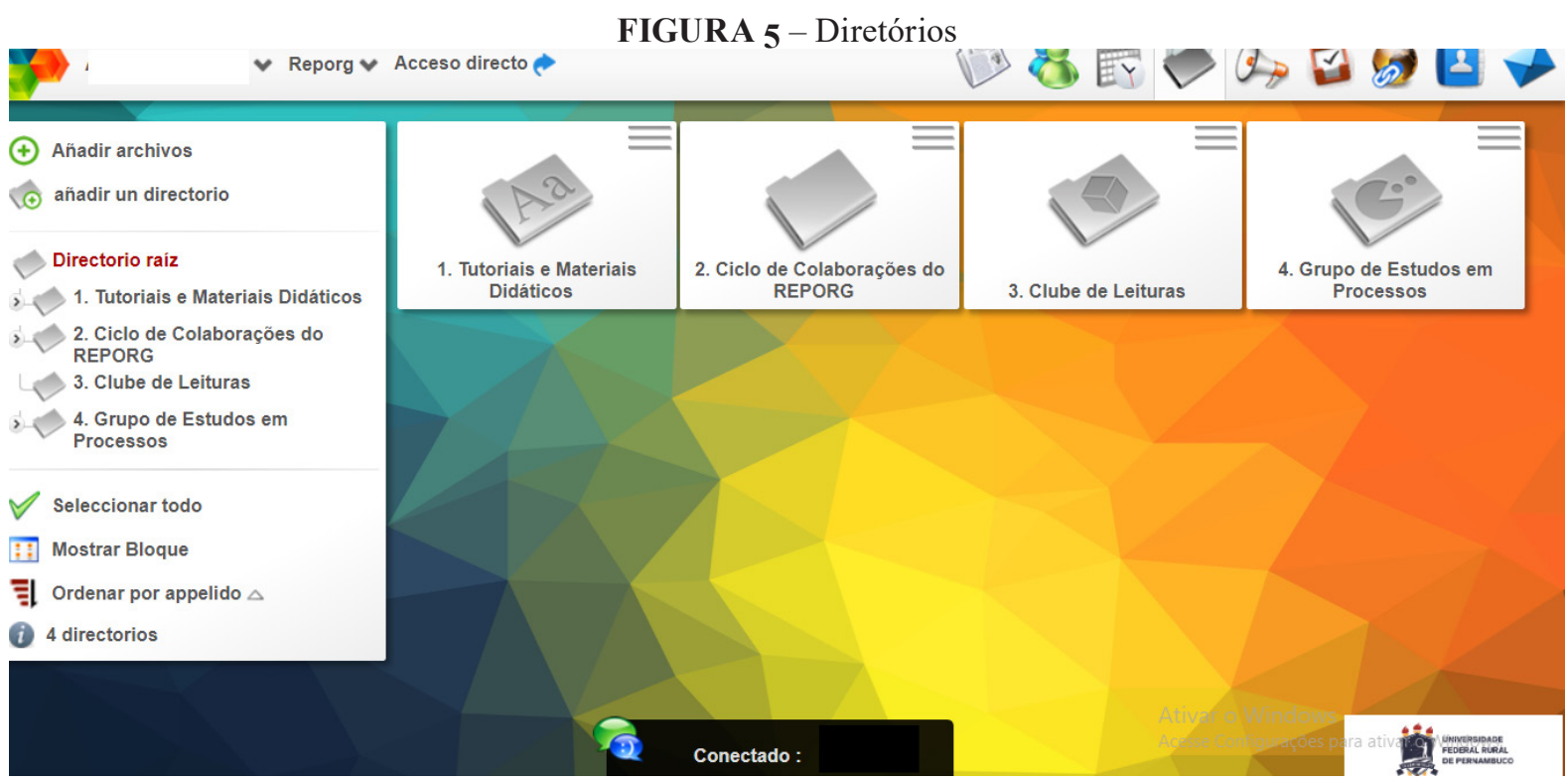

Fonte: site do REPORG (UFRPE, 20I8).

É nesse espaço que os colaboradores de diversas universidades irão organizar os processos por eles apresentados (Figura 5), pois como já se sabe, dentro de uma instituição existem diversos tipos de processos e neste diretório serão organizados a fim de que todos os usuários alocados nas diversas universidades possam acessá-los de forma prática e eficiente.

Ao entender então toda a estrutura e história do repositório on-line da UFRPE, busca-se então compreender quais os fatores críticos de sucesso para a execução dele. Ao perguntar para o stakeholder I sobre a relação do REPORG com o Plano de Desenvolvimento Institucional (PDI) da UFRPE, uma vez que será a primeira universidade a utilizar o REPORG, foi possível observar a necessidade que toda a ação de mudança organizacional precisa responder a este plano e a partir desse momento que se foi construindo os fatores críticos de sucesso deste repositório para a instituição, como observa-se no quadro 3 .

QUADRO 3-Entrevista com stakeholder I quanto a relação do PDI com o Repositório on-line. Qual a relação do repositório on-line com o PDI da instituição?

Com relação a vinculação ao PDI é para fazer a articulação interinstitucional para assim formalizar esse compromisso com a instituição. A UFRPE não tem um escritório de processos, existe uma coordenadoria de processos e estruturas de processos organizacionais situada na Pró-reitora de Planejamento (PROPLAN) que possui apenas duas servidoras que estão mais direcionadas a regularização de regimentos e proteção da estrutura organizacional. Busca-se então institucionalizar em forma de extensão na UFRPE iniciando com a inserção no Sigproj que é um sistema Nacional do Ministério da Educação e da Cultura (MEC) que estão alocados todos os projetos de extensão.

A relação com o PDI é para tornar a implementação mais segura, pois lida diretamente com mudança organizacional, e quando se fala de mapeamento de processos se torna obvio o interesse em tornar cada vez mais eficaz a forma que se faz para se apropriar desses processos.

Sabe-se com isso que para um melhor funcionamento deve caminhar junto da natureza estratégica da instituição, pois qualquer esforço de mudança organizacional é estratégico, fazendo-se então necessário para a construção de uma gestão de processos estruturada na UFRPE fazer esse diálogo com o PDI, reconhecendo como sendo norteador de ações estratégicas mais centrais. Com esse elo as contribuições do repositório on-line de processos contribuirão de forma direta com a execução do planejamento estratégico proposto.

Fonte: Elaborado pelos autores. 
Como apresentando no quadro 3, para a construção do repositório da UFRPE, visando os Fatores Críticos de Sucesso, deve-se o cuidado de atender aos objetivos do PDI (UFRPE, 20I2) que vai do ano de 2013 a 2020.

O primeiro objetivo do PDI informa que a instituição deve contribuir com transformação social sustentável a partir de políticas de melhoria das atividades de ensino, pesquisa e extensão. E como resposta apresenta-se a seguinte ação do repositório de processos on-line, fazer o estudo e o aperfeiçoamento dos processos organizacionais, configurando-se como meio indispensável à gestão da transformação institucional, permitindo análises muito precisas sobre os significados e os impactos socioambientais das atividades universitárias.

O segundo objetivo do PDI é o de "valorizar e promover o envolvimento de todos que compõem a Instituição na contínua construção de uma universidade pública de excelência, democrática, plural e transparente" (UFRPE, 20I2, p. 25). Para então se obter as melhores práticas para o mapeamento de processos organizacionais se faz necessário reconhecer a importância fundamental no diálogo franco e aberto com os membros de uma organização, visando entre outros aspectos a transparência e o equilíbrio na distribuição de responsabilidades.

O terceiro objetivo do PDI da UFRPE é "Fomentar parcerias institucionais, promovendo a inovação, a construção e a popularização de saberes científicos, tecnológicos e culturais" (UFRPE, 20I2, p. 25). Dando como resposta o repositório on-line da UFRPE propõe-se a obter a colaboração de engenheiros, administradores e economistas, de cinco órgãos da UFRPE, sendo reveladora do grau de prioridade dado ao caráter de parceria.

O quarto objetivo do PDI trata da participação da comunidade acadêmica na gestão estratégica, tendo assim as ações do repositório mais uma vez uma frente que busca as melhores práticas para mapeamento de processos organizacionais que reconhecem importância fundamental no diálogo franco e aberto com os membros de uma organização, também em função de constituir clara oportunidade de aprendizagem organizacional, indispensável ao fortalecimento da gestão estratégica (UFRPE, 20I2).

O quinto objetivo do PDI por sua vez, diz que a universidade deve valorizar a imagem e a memória institucional. Ao assumir a iniciativa de liderar a ideia do Repositório on-line a UFRPE ganha assim maior visibilidade e notoriedade diante de sua competência (UFRPE, 20I2).

O sexto objetivo do PDI apresenta a necessidade de modernizar a gestão da tecnologia da informação e comunicação na universidade. Diante deste fato o mapeamento e a revisão de processos organizacionais trazem ganhos de curto e médio prazos nessa área (UFRPE, 20I2).

Por fim o sétimo objetivo do PDI apresenta a necessidade que pode ser o maior ponto de partida para a execução do repositório on-line quando se apresenta a necessidade de adequar a infraestrutura e sua gestão às melhores práticas universitárias e à busca pela excelência. Com isso, se executada, a proposta não apenas constituirá uma das melhores práticas de articulação 
e cooperação institucional nas IFES (benchmarking); ela também valorizará, através das posteriores parcerias interinstitucionais, as experiências exitosas na gestão de processos de outras universidades, com ganho para todo o sistema.

Ao tratar com o stakeholder 2 foi possível constatar que o caminho para o compartilhamento dos processos da UFRPE como sendo pioneira em colaborar dentro do repositório on-line já está sendo realizada, como pode-se observar no quadro 4.

QUADRO 4 - Entrevista com stakeholder 2 sobre os caminhos do REPORG na UFRPE Quais os caminhos que a UFRPE já apresenta para que o repositório on-line seja de fato utilizado?

Conhecer o desenho do processo é algo que já vem sendo discutido na implementação do sistema eletrônico de informação SIPAC o problema original que tem que enfrentar é que não temos o mapeamento dos processos da instituição ficando muito na memória viva das pessoas o sistema com os processos mapeados vai então permite encaminhar os processos no fluxo que foi determinado através dos desenhos. Hoje tem-se quatro processos mapeados da PROPLAN.

Fonte: Elaborado pelos autores.

Ter a execução das modelagens dos processos, como apresentado no quadro 4, da UFRPE de fato já é um bom início para o repositório progredir. Esse conhecimento dos problemas que se vem enfrentando, com a necessidade real de se ter esses desenhos dos processos para uma melhor organização, é uma tomada de consciência necessária para que assim as outras ações aconteçam.

Existem na instituição ações efetivas para que esses processos sejam geridos de forma eletrônica, de não ter mais papel, essa forma de execução futura do gerenciamento de processos é possível observar no quadro 5.

QUADRO 5 - Entrevista com stakeholder 2 quanto a colaboração entre universidades para um repositório online de processos.

É perceptível o compartilhamento entre universidades como uma colaboração satisfatória?

A ideia colaborativa do repositório on-line é muito viável, contudo, há de se fazer uma checagem por causa do regimento interno de cada instituição. Tendo claro que para ter um sistema eletrônico de informação, primeiramente, é necessário fazer o mapeamento de processos.

Fonte: Elaborado pelos autores.

A resposta apresentada no quadro 5 afirma que, com a colaboração, tanto esse caminho de construção da modelagem interna como também da própria aplicação do desenho da modelagem fica mais coeso, pois uma vez debatido e visualizados os entraves que ocorreram em outras universidades que já passaram processos semelhantes, tende-se a não cometer mais os mesmos erros.

Mas para se efetivar o compartilhamento dos processos, é necessária uma boa aceitação primeiramente dentro da universidade, sendo que os clientes internos devem acreditar no processo que se apresenta e perceberem a sua viabilidade, como apresenta o entrevistado no quadro 6. 
QUADRO 6 - Entrevista com stakeholder 2 quanto aos clientes internos.

Qual a importância da integração dos clientes internos?

Sabe-se também que diante da cultura conservadora que temos dentro da universidade essa implementação deve ocorrer aos poucos e os benefícios tendem a superar as necessidades percebendo que aquela inovação ajuda a todos para melhor execução do trabalho. Facilita e agiliza o processo sendo assim um caminho sem volta

Fonte: Elaborado pelos autores.

Como visto no sexto objetivo do PDI se faz necessário modernizar a gestão e como o stakeholder 2 afirmou no quadro 6 esse caminho é sem volta, pois quando se percebe que este novo alinhamento só trará benefícios não é mais possível se ater a práticas antigas (UFRPE, 20I2).

Assim, uma gestão por processos tem a possibilidade de trazer o resultado esperado quando o ambiente corporativo é favorável e a sua estrutura global interliga outros instrumentos administrativos, como por exemplo: planejamento estratégico, sistema de participação, qualidade total, relatórios gerenciais, estrutura organizacional, logística e comprometimento de servidores. Portanto, é fundamental aos gestores buscar atingir a otimização, mediante a participação tanto do mais alto nível decisório da organização até o mais simples nível executivo (DAVENPORT, I990).

Entre as lições aprendidas no processo de implantação do repositório on-line na UFRPE está o compartilhamento de conhecimento, informações e práticas, tanto entre as IFES quanto entre diferentes departamentos e profissionais envolvidos no processo de levantamento dos processos na própria UFRPE. A instituição também ganha um papel de destaque pelo protagonismo e inovação, junto ao FORPLAD, na proposição de uma gestão integrada e que busca compartilhar melhores práticas de gestão, através do compartilhamento de dados e experiências.

\section{CONSIDERAÇÕES FINAIS}

O tema gestão de processos é um tema contemporâneo e ao se tratar da gestão das organizações, tornou-se uma ferramenta de trabalho necessária para seu melhor funcionamento. Nesse contexto, os Fatores Críticos de Sucesso (FCS) apresentam os melhores percursos dentro do caminho dos processos, retirando falhas e ambiguidades e podem auxiliar na formação de competências para as pessoas que irão trabalhar diretamente com a gestão de processos (ROCKART, I979).

O repositório on-line se apresenta como uma ferramenta importante de conformidade e pode vir a representar um padrão dentro da gestão estratégica e de planejamento da UFRPE. O repositório poderá promover o alinhamento do processo com as estratégias e valores da Universidade, como também a integração dos processos de determinados grupos com toda a universidade. Também, se torna possível com essa integração e colaboração de processos, a priorização, coordenação e promoção de melhorias entre os projetos, sendo possível manter atualizada a documentação de execução dos processos, não deixando de zelar pelo constante aprimoramento dos processos. 
O repositório on-line também permite realizar e manter atualizada a análise de riscos dos processos, gerenciando os planos de contingência e desenvolvendo atividades de controle específicas. Sendo muito importante também saber gerir os direitos de acesso dos usuários, zelando pela atualização e revisão periódica destes, sempre identificando, atualizando e organizando as novas documentações necessárias de sistemas de informação. Com isso, garante o cumprimento das metas estabelecidas para os processos, com monitoração constante dos indicadores do desempenho.

Destacam-se como limitações do presente artigo a descontinuidade das atividades de levantamento dos processos, em virtude de questões administrativas da UFRPE e da própria dificuldade de articulação do FORPLAD, o que impossibilita a apresentação de resultados efetivos da iniciativa. Também a falta de possibilidade de participação de outros atores envolvidos no processo de levantamento de processos. Como sugestão de trabalhos futuros, fica a ampliação do estudo para outras instituições de ensino que tenham aplicado metodologia semelhante.

\section{REFERÊNCIAS}

ASSUNÇÃO, Maria Aparecida de; MENDES, Paule Jeanne Vieira. Mudança e gestão de processo em organização público. V Congreso Internacional del CLAD sobre la Reforma del Estado y de la Administración Pública. Santo Domingo, Rep. Dominicana, p. $24-27$, 2000.

BALDAM，R.L.; VALLE， R.A.B.; PEREIRA， H.R.M; HILST， S.M.; ABREU， M.P. Gerenciamento de processos de negócios: BPM-Business Process Management. São Paulo: Érica, 2007.

BERTUCCI, Janete Lara de Oliveira. Ambiente, estratégia e performance organizacional no setor industrial e de serviços. Revista de Administração de Empresas. São Paulo, v.45, n.3, p.IO-24, 2005.

BRASIL, Constituição de I988. Emenda Constitucional n I9, de 04 de junho de I995. Modifica o regime e dispõe sobre princípios e normas da Administração Pública, servidores e agentes políticos, controle de despesas e finanças públicas e custeio de atividades a cargo do Distrito Federal, e dá outras providências. In: Constituição Da República Federativa Do Brasil. I7.ed. São Paulo: Atlas, 200I.

BRASIL, Lei n ${ }^{0}$ I3.460 de 26 de junho de 20I7. Participação, proteção e defesa dos direitos do usuário dos serviços públicos da administração pública. Disponível em: https://www.planalto. gov.br/ccivil_03/_ato20I5-20I8/20I7/lei/1I3460.htm. Acesso em: I6 abr. 2019.

CAREGNATO, Rita Catalina Aquino; MUTTI, Regina. Qualitative research: discourse analysis versus content analysis. Texto \&amp; Contexto - Enfermagem, v. I5, n. 4, p. 679-684, 2006.

CHIZZOTTI, Antonio. Pesquisa em Ciências Humanas e Sociais. São Paulo: Cortez, I99I. 
DAVENPORT, Thomas. H.; SHORT, James. E. The new industrial engineering: information technology and business process redesign. Sloan Manage Rev., v. 3I n. 4: p. II-27, I990.

DETLOR, B. Information management. International Journal of Information Management, n. 30, p. I03-IO8, 2010.

ESPANTOSO. José Juan Péon. A gestão dos espaços informacionais em ambientes de arquitetura da informação organizacional. Informação \& Sociedade: Estudos, João Pessoa, v.22, n.3, p. 33-39, 2012.

FONTES, E. L. G. Praticando a segurança da informação. Rio de Janeiro: Brasport, 2008.

GONÇALVES, José Ernesto Lima. As empresas são grandes coleções de processos. RAE Revista de Administração de Empresas. São Paulo: ANPAD. v. 40, n. I, p. 6-19, 2000.

GUISE, J. M.; WINTER, S.; FIORE, S. M.; REGENSTEINER, J. G.; NAGEL, J. Organizational and training factors that promote team science: A qualitative analysis and application of theory to the National Institutes of Health's BIRCWH career development program. Journal of clinical and translational science, 2017.

HARRISON-BRONINSKI, K. Dealing with Human-Driven Processes. In: Broke J. V.; Rosemann, M. (eds). Handbook on Business Process Management, v. 2. Heidelberg: Springer, 2014 .

JURISCH, Marlen; IKAS, Christian.; WOLF, Petra; KRCMAR, Helmut. Key Differences of Private and Public Sector Business Process Change. E-Service Journal, v.9 n.I, 20I3. Disponível em: <https://www.jstor.org/stable/Io.2979/eservicej.9.I.3.> Acessado em: 20 abr. 2019.

LEITE, José Alfredo Américo. Metodologia de Elaboração de Teses. São Paulo: Editora McGraw-Hill do Brasil, 1978.

LOPES, M. A. B.; BEZERRA, M. J. S. Gestão de processos: fatores que influenciam o sucesso na sua implantação. XXVIII Encontro Nacional de Engenharia de Produção, Rio de Janeiro, 2008.

MAIA FILHO, Luiz Flávio Arreguy; PINHO, Marco Aurélio Benevides de. Entrevista e Descoberta de Processos em Ambientes Desafiadores: uma releitura econômico-comportamental inspirada no MINDSPACE. Revista Gestão.Org, v. I6, Edição Especial, p. 293-306, 2018.

McGEE, J.; PRUSAK, L. Gerenciamento estratégico da informação: aumente a competitividade e a eficiência de sua empresa utilizando a informação como uma ferramenta estratégica. Rio de Janeiro: Campus, 1994.

O'BRIEN, James A. Sistemas de informação e as decisões gerenciais na era da internet. Tradução de Cid Knipel Moreira. São Paulo: Saraiva, 2002. 
RODRIGUEZ, Martius V. Rodriguez y. Gestão Empresarial: Organizações que Aprendem, Rio de Janeiro, Qualitymark, 2002.

ROCKART, J. F. Chief Executives define their own data needs. Harvard Business Review, v. 57, n. 2, p. 8I-92, Mar./Apr. 1979.

SMART, P. A.; MADDERN, H.; MAULL, R. S. Understanding business process management: implications for theory and practice. British Journal of Management. p.I-I7, 2008.

SORDI, J. O. Gestão por processos: uma abordagem da moderna administração. São Paulo: Saraiva, 20I4.

TRAUTH, E. M. The Evolution of Information Resource Management, Information \& Management, v. I6, p. $257-268$, 1989.

TRKMAN, P. The critical success factors of business process management. In: International Journal of Information Management. v. 30, p. I25-I34, 2010.

UFRPE. Plano de Desenvolvimento Institucional UFRPE 2013-2020. Versão Revista e Atualizada. Resolução n ${ }^{\circ} 36 / 2018$ - Conselho Universitário. 20I8. Disponível em: $<$ http://proplan. ufrpe.br/sites/www.proplan.ufrpe.br/files/pdi_20I8-08-2I.pdf >. Acesso em: oI abr. 2019. 